\title{
In memoriam: Semblanzas de Martha Aurora Bechis (1929-2017)
}

Martha Bechis falleció en Buenos Aires el 14 de septiembre de 2017. Tuvo una larga vida, compañeros y amigos muy queridos, fue una investigadora de las ciencias sociales cuando las mujeres de su generación estaban comenzando a abrir caminos en esos campos. Estudió en la Facultad de Filosofía y Letras de la Universidad de Buenos Aires (en adelante UBA) en los años de 1950 y conservó por décadas la amistad de sus compañeros y compañeras de estudios de esa etapa. Por unos años fue profesora en esa Facultad y luego fue a vivir a Puerto Rico donde también se dedicó a la docencia y a la investigación. Regresó a nuestro país en 1988 y desde entonces se dedicó a la Etnohistoria del área pan-araucana.

La obra de Martha Bechis ha quedado reunida en dos importantes compilaciones que ella misma supervisó con la re-publicación de gran parte de sus numerosos artículos y capítulos de libros: Piezas de etnohistoria del sur sudamericano (Madrid, Consejo Superior de Investigaciones Científicas, 2008) y Piezas de etnohistoria y de antropología histórica (Buenos Aires, Sociedad Argentina de Antropología, 2010). También, en 2011 la revista Corpus publicó digitalmente su tesis de $P h D$ como reconocimiento de la notable influencia que ha tenido ese trabajo en las investigaciones posteriores.

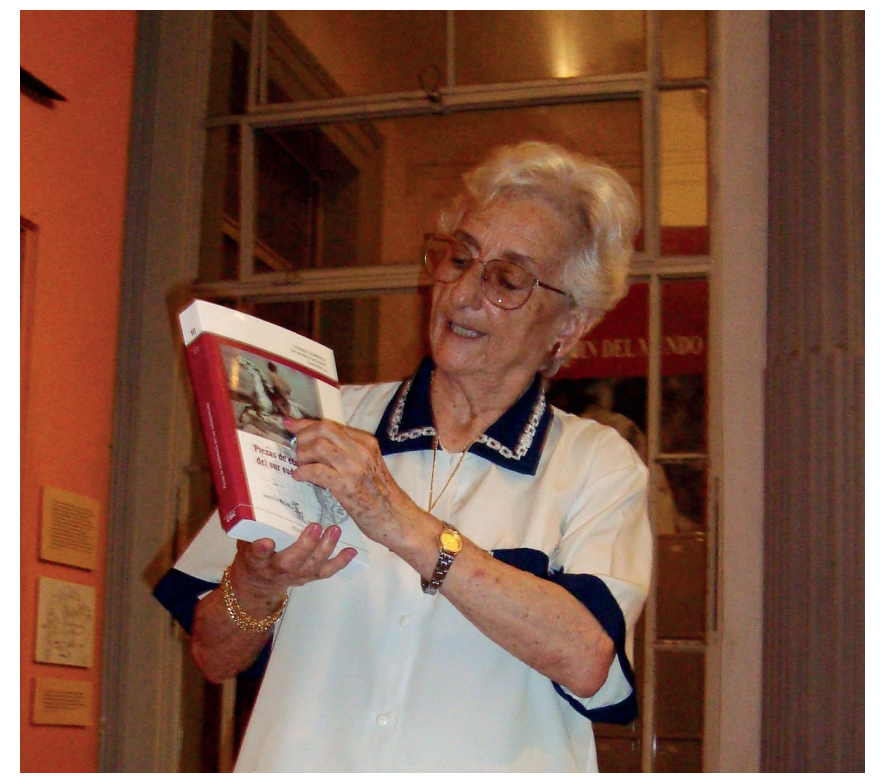

Martha Bechis, presentación del libro Piezas de etnohistoria del sur sudamericano. Buenos Aires, Museo Etnográfico, marzo de 2009. 


\section{Semblanza 1: Martha en Filosofía y Letras, por Amanda Toubes}

No quiero escribir sobre Martha Bechis muerta recientemente. Quiero compartir con los lectores posibles de esta revista, Memoria Americana. Cuadernos de Etnohistoria, algunas pinceladas históricas, antiguas, de lo que significa para mí esta especial y entrañable compañera.

Nos conocimos allá lejos, en los años 50, en los pasillos sombríos de la Facultad de Filosofía y Letras de la calle Viamonte: clases de idioma latín y griego, de Historia de la Filosofía, de Lógica. Compartimos intereses diversos, aburrimientos y algunos destellos que fueron equilibrados con las interminables charlas en el café Florida. Allí encontramos la parte vital y amorosa de nuestros desvelos y curiosidades, compañerismos varios, discusiones largas y posiblemente -sin sentido para otros- se fueron perfilando algunos esbozos de nuestras decisiones político-sociales. Ese querido grupo era de márgenes movibles en gestos, análisis y discusiones. Allí estaban Ángel Capelletti con su sabiduría docente filosófica, Haroldo Conti con sus narraciones llenas de picardías pueblerinas, Jaime Rest con su maravillosa erudición literaria, Julio Ameller con sus silencios cargados de inquietud filosófica, Paulina Bidner con su seriedad y largas ironías, Rubén Massera y sus digresiones lógicas llenas de fantasía...

Cuánto tiempo perdido y ganado en medio de brumas y sonidos de futuros impredecibles. Aunque Martha, de pronto, ponía sobre la mesa informes y decisiones desde otro lugar: su trabajo en el Centro de Estudiantes de Filosofía y Letras, en donde estaba a cargo de la Secretaría de Ateneos (1952). Entonces transcurrían las reuniones de los sábados a las 15 horas en el sótano de la calle Las Heras y las situaciones concretas a resolver; entre ellas, la preparación de las primeras peñas literarias y filosóficas donde demostraba su eficiencia y disciplina. Para mí, Martha siempre conservó ese estilo pedagógico sociocultural con una mezcla de amabilidad y seriedad, era afectuosa y solidaria en formas imperceptibles, silenciosa y alerta en todas las circunstancias. Doy fe de ello.

Su trabajo meticuloso en la cátedra de Psicología Social del profesor Enrique Butelman, en la nueva carrera de Psicología de la Facultad de Filosofía y Letras, se interrumpe con el golpe militar de junio de 1966, estallido siempre temido en esos difíciles años con su panorama de represión, de renuncias de docentes y de exilios internos y externos. Martha parte con Julio Ameller y otros colegas a Puerto Rico, pensando que sería por poco tiempo. Allí desarrollará clases en institutos universitarios, estudiará y hará su doctorado. Sin embargo, siempre estuvo al lado nuestro, en los tiempos dramáticos de la dictadura cívico-militar de 1976-1983, siempre presente con su solidaridad y su denuncia militante a distancia, como tantos otros compañeros, silenciosamente, caminó y caminó pasillos y oficinas para denunciar sin alharacas la tragedia argentina.

Luego a su regreso, ya en democracia (1985), no rehusó asumir la responsabilidad administrativa y política de la reorganización del Instituto de Sociología de la Universidad de Buenos Aires, en medio de grandes dificultades, junto con otros colegas: Hilda Herzer, Ruth Sautú, Hilda Kogan, Ana Lía Kornblit, Inés Izaguirre, Norma Giarraca, Juan Carlos Marín. 
Aquí comienza la otra etapa de Martha: la docencia e investigación en diversas universidades e institutos de investigación argentinos sobre los temas que más le interesaban, como por ejemplo el desarrollo de la idea de la Nación Indígena.

Suspendo aquí y la acompaño con las palabras de un poema:

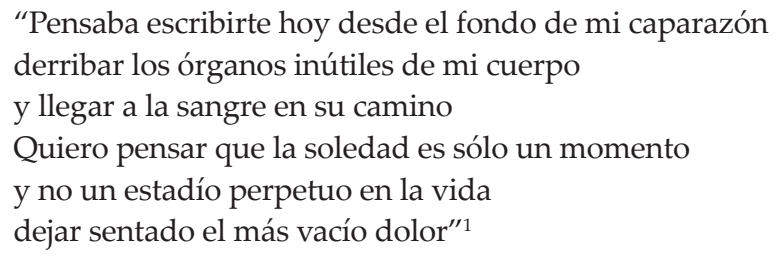

\section{Semblanza 2: Martha en Londres, por Ruth Sautu**}

En agosto de 1962 Martha sacó una beca para estudiar Antropología con Raymond Firth en la London School of Economics and Political Science (en adelante, LSE). Su referente en esa institución era Sutti Ortiz, hija de Reisig. A fines de ese año viajó su esposo Julio Ameller, quién también se inscribió como nosotras dos en el programa de doctorado. En la LSE compartimos los cursos y las charlas. Eran años en los cuales todavía se podía vivir en la vieja Inglaterra de las pounds, shillings y pennies, del smog, y también de un estado de bienestar que incluía un sistema de salud pública como no he vuelto a ver en mi vida -e incluyo actuales pre-pagas. Para argentinos típicos no era fácil adaptarse a la falta de calefacción y de agua caliente abundante a lo que estábamos acostumbrados -había que usar pennies o shillings en un meter para que funcionaran los calefactores.

Pero Martha siempre nos mostraba el lado bueno de las cosas o las situaciones. A la peor comida inglesa le encontraba un gusto agradable. Vivía la experiencia de habitar lugares fríos e incómodos como si estuviera en un hotel de lujo. Muchas casas no tenían ducha ni bañadera y aún la experiencia de ir a un baño público a ducharse le parecía una aventura entretenida.

Martha hizo los cursos de antropología durante ese año calendario y regresó a Buenos Aires, mientras Julio se quedó hasta terminar su PhD. Con el golpe de Onganía ambos se quedaron sin laburo y a fines de 1966 aceptaron ir a Puerto Rico.

\section{Semblanza 3: Martha de regreso en Buenos Aires, por Lidia Nacuzzi ${ }^{*}$}

Con Martha nos conocimos -seguramente- durante el I Congreso Internacional de Etnohistoria (en adelante CIE) que se realizó en la Facultad de Filosofía y Letras de la UBA en julio de 1989. Aunque no conservábamos el recuerdo de nuestro encuentro en esas jornadas, nuestros temas de investigación nos reunieron muy pronto, café de por medio, y encontramos rápidamente un diálogo sincero y ameno, hablando de todo un poco, también de las cuestiones

\footnotetext{
** Instituto de Investigaciones Gino Germani, Facultad de Ciencias Sociales, Universidad de Buenos Aires. Profesora Emérita titular en la misma Facultad. Buenos Aires.

*** Centro de Investigaciones Sociales (CIS) - Consejo Nacional de Investigaciones Científicas y Técnicas (CONICET)/ Instituto de Desarrollo Económico y Social (IDES). Buenos Aires. E-mail: lidianacuzzi@yahoo.com.ar
}

1. Peras del Olmo de Alelí Puerto.
Provincia del Chubut, Tutú Carreta Ediciones (2017). 
extra-académicas. En algún momento de esos años de la década de 1990, superando el enojo con risas, creamos la "orden de los caballeros de las comillas caídas" para referirnos a los -y las- colegas que no citaban correctamente las investigaciones previas.

De las actividades más formales que compartimos se destacan algunos momentos. En primer término, la coordinación de una mesa temática en el V CIE de Salta en 1998, durante la cual alternadamente nos cansamos, renegamos, discutimos y paseamos en armonía y compañerismo notable. Luego, volvimos a coincidir como conferencistas en Temuco al año siguiente. Allí, a fines de mayo, compartimos también el lugar de alojamiento en una casa de familia de la ciudad. En primorosos dormitorios, con olor a cera y edredones de fundas floreadas, pude observar el entusiasmo adolescente de Martha por esa corta estadía en la capital de la Araucanía. Por esos años también cursamos un seminario sobre tratados de paz con los indígenas en la facultad de Derecho de la UBA. Allí estaba Martha en su rol de alumna, discutiendo y reflexionando sobre las propuestas del profesor, la imaginé como estudiante de Filosofía en la UBA de los años 1950.

En 2008 apareció una primera compilación de los trabajos de Martha publicada por el Consejo Superior de Investigaciones Científicas de Madrid. Cuando se iniciaba 2009 organizamos la presentación de ese libro en el Museo Etnográfico de la UBA y festejamos su cumpleaños número 80. Allí conocí a parte de su familia y a sus amigas de la vida, otras profesionales que habían compartido con ella sus años de estudio y docencia en la Facultad de Filosofía y Letras de la UBA, entre ellas Amanda Toubes y Ruth Sautu.

En ocasión de presentar ese libro, la propia Martha me resumió por escrito su trayectoria institucional como sigue. Estudió en la UBA en la que obtuvo el grado de Profesora de Enseñanza Secundaria, Normal y Especial en Filosofía de la Universidad de Buenos Aires, en 1955. En la UBA también comenzó su carrera docente en 1959, en 1966 había alcanzado el cargo de profesora adjunta interina, cuando renunció debido al golpe militar de aquel año y a la toma de la universidad por las fuerzas militares. En 1983 obtuvo su PhD en Antropología en la New School for Social Research de Nueva York, con su tesis "Interethnic relations during the period of nation-state formation in Chile and Argentina: from sovereign to Ethnic".

Desde 1967 a 1987 desarrolló su actividad docente en el Colegio Universitario de Arecibo, perteneciente a la Universidad de Puerto Rico. Esa universidad la becó entre 1973 y 1976 para realizar sus estudios de doctorado en la New School for Social Research de Nueva York. Por un año se desempeñó como Decana de Asuntos Académicos del Colegio Universitario de Arecibo para después reintegrarse a su país en 1988. En Puerto Rico también ofreció clases en la Universidad Interamericana y en el Departamento de Instrucción del gobierno de ese territorio y fue ponente en varios congresos y jornadas en Estados Unidos. De regreso a la Argentina, fue directora interina del antiguo Instituto de Sociología de la Universidad de Buenos Aires (UBA). También ofreció clases y conferencias en el Instituto de Historia de la UBA, en la Universidad Nacional del Sur, en el Instituto Nacional de Antropología y Pensamiento Latinoamericano y en la Universidad Nacional del Centro de la Provincia de Buenos Aires. Fue vocal de la Comisión Directiva de la Asociación Argentino-Chilena de Estudios Históricos e Integración Cultural. Hasta 2010 se desempeñó como Investigadora Titular en el "Instituto de Investigaciones Gino Germani" de la Facultad de Ciencias Sociales de la UBA. También participó del 
Grupo de Estudios e Investigaciones de Procesos Políticos (GEIPP) con sede en el Instituto de Historia "Emilio Ravignani" (UBA) y fue miembro de la Red de Estudios Rurales (RER) del mismo Instituto, desde 1995. En la Universidad Nacional de Río Cuarto, provincia de Córdoba, fue Coordinadora Académica del Taller de Etnohistoria de la Frontera Sur (TEFROS) y Coordinadora del Comité Editorial de la Revista Tefros publicada en línea por la misma Universidad. En 2007 fue distinguida con la consideración al Mérito Científico por el Centro de Investigaciones Precolombinas del Instituto Superior del Profesorado Joaquín V. González.

Cuando le propuse la compilación de 2010 para la Sociedad Argentina de Antropología, la emprendió sin dudar y con gran energía, buscando mostrar su historia en la investigación. Como ella misma lo expresó en el prólogo, quiso exponer "el esfuerzo de instalar la Etnohistoria como una disciplina particular con un lugar y contenido propio entre las Ciencias Sociales". Sus artículos y conferencias han contribuido al conocimiento histórico de las sociedades indígenas del área pan-araucana con hipótesis sugerentes, aportando una mirada absolutamente despojada de etnocentrismo y complejizando conceptos teóricos que provenían de la geopolítica, la sociología, la historia y la antropología. Ha explorado en la teoría del juego, en la cibernética, en el análisis del discurso y de las formaciones del estado, en las acciones diplomáticas y en las relaciones de parentesco, en las situaciones de resistencia y dominación, entre otros posibles caminos para fundamentar sus argumentos y conclusiones. Su tratamiento de las fuentes históricas fue asimismo ejemplar en el sentido de confrontar los datos, establecer su veracidad y discutir sus alcances de manera implacable para con sus propias hipótesis. Martha podía referirse minuciosamente a una historia acotada espacial y temporalmente -por ejemplo, los tres tratados de paz acordados en el siglo XVIII con los grupos indígenas de la Pampa, los conflictos de la primera época de la revolución de 1810 entre "criollos republicanos" e indígenas o el sitio del cacique Yanquetruz a la Villa de Concepción en 1831, para nombrar algunas- y relatar los hechos casi como en una crónica para luego desprender de ellos hipótesis sugestivas y, en su demostración, realizar un aporte teórico abarcador que por su coherencia y relevancia sería imposible de soslayar en trabajos futuros.

Queda mucho trabajo por hacer en la senda que Martha abrió. Seguramente sus aportes nos seguirán inspirando.

\section{Semblanza 4: Martha en el Taller de Etnohistoria de la Frontera Sur, por Marcela Tamagnini ${ }^{* * *+*}$}

La impronta de Martha Bechis se ha dejado sentir también en las universidades y centros de investigación del interior de Argentina, a través de su enérgica participación en diferentes actividades de investigación y docencia. En una de ellas, las Segundas Jornadas de Historia y Cultura Ranquelinas realizadas en Santa Rosa (La Pampa) en 1994, conocí personalmente a Martha. Volvimos a encontrarnos, creo, en las Terceras Jornadas realizadas dos años después en Venado Tuerto (Santa Fe) y en las siguientes, en la pequeña ciudad de La Carlota (Córdoba), allá por 1998. En el medio, mantuvimos un nutrido intercambio epistolar y de trabajos que permitió afianzar nuestro vínculo. Me consta que algo similar ocurrió con los colegas de la Universidad Nacional del Sur (Bahía Blanca) y los de la Universidad Nacional de Luján.

**** Laboratorio de Arqueología y Etnohistoria, Departamento de Historia, Facultad de Ciencias Humanas, Universidad Nacional de Río Cuarto. Río Cuarto. E-mail: marcela.tamagnini@gmail.com 
Su preocupación por la promoción de diferentes grupos y reuniones de investigación se cristalizó finalmente con la fundación del Taller de Etnohistoria de la Frontera Sur (TEFROS), grupo que conformamos a fines del 2002 en el campus de la Universidad Nacional de Río Cuarto con el fin de discutir diversas problemáticas ligadas a la Etnohistoria del espacio correspondiente a la gran Frontera Sur de la América del Sur. Su labor en la fundación de TEFROS, y luego como su Secretaria Académica, fue sumamente valiosa, máxime si tenemos en cuenta que no se trataba de una tarea sencilla porque quienes lo componíamos trabajábamos e investigábamos en distintos centros institucionales, procedíamos de diversos campos disciplinares, teníamos un desigual manejo de los soportes informáticos y escasos recursos para solventarlos. Atenta a estas dificultades Martha encaró la cuestión con un espíritu de cruzada sorprendente, sin escatimar ningún tipo de esfuerzos -que iban desde subirse a cualquier micro de los llamados "lecheros" para llegar a la bastante lejana Río Cuarto cuantas veces fuera necesario, a internalizar el "abc" de la edición de revistas científicas- siempre motivada por su objetivo de hacer de la producción etnohistórica una rama del saber verdaderamente interdisciplinaria. Y como si todo esto fuera poco, Martha enfrentó con valentía la tarea de escudriñar tempranamente las potencialidades y límites de un soporte como la web que, en los inicios del milenio, no parecía tan sencillo de transitar sobre todo para los que venimos de la cultura del papel.

Fue su firme voluntad la que permitió que rápidamente nos pusiéramos en marcha, publicando primero un Boletín electrónico que luego se convirtió en la Revista TEFROS, con sus ya dieciséis volúmenes publicados de manera ininterrumpida, gracias a los aportes de sus más de 150 miembros que año a año hacen llegar sus trabajos para compartirlos con el resto de la comunidad científica.

Desde el Taller de Etnohistoria de la Frontera Sur (TEFROS) recordamos a Martha Bechis y destacamos el contenido y la importancia -pasada, presente y futura- de su obra que está destinada a perdurar y marcar el rumbo de los estudios etnohistóricos en el Cono Sur. 